\title{
Vitamin D Level in Pregnant Women Depends on Age and Weight Before and During Pregnancy
}

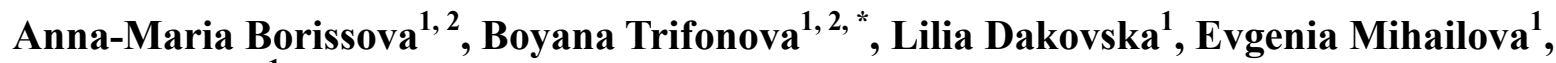 \\ Mircho Vukov ${ }^{1}$ \\ ${ }^{1}$ Clinic of Endocrinology, University Hospital Sofiamed, Sofia, Bulgaria \\ ${ }^{2}$ Medical Faculty, Sofia University St. Kliment Ohridski, Sofia, Bulgaria \\ Email address: \\ boianatri@abv.bg (B. Trifonova) \\ ${ }^{*}$ Corresponding author

\section{To cite this article:} \\ Anna-Maria Borissova, Boyana Trifonova, Lilia Dakovska, Evgenia Mihailova, Mircho Vukov. Vitamin D Level in Pregnant Women \\ Depends on Age and Weight Before and During Pregnancy. Clinical Medicine Research. Vol. 9, No. 3, 2020, pp. 54-58. \\ doi: $10.11648 /$ j.cmr.20200903.12
}

Received: April 25, 2020; Accepted: May 25, 2020; Published: June 4, 2020

\begin{abstract}
The AIM of our study was to evaluate the association between vitamin D levels and age, body weight before pregnancy and during the screening and the term of pregnancy. MATERIALS AND METHODS: We investigated 547 unselected pregnant Bulgarian women, mean age $30 \pm 5$ years, median 30 years (18-47 years). The distribution of pregnant women according to their age is as follows: $18-22$ y $-33(6 \%), 23-27$ y $-115(21 \%), 28-33$ y $-219(40 \%), 33-37$ y -128 (23.4\%), 38-42 y - $46(8 \%), 43-47 \mathrm{y}-6(1.1 \%)$. The allocation according to trimesters of pregnancy was: first trimester - 111 (20.3\%), second trimester - $275(50.4 \%)$, and third trimester - $161(29.3 \%)$. In the current study we introduced four categories of $25(\mathrm{OH}) \mathrm{D}-<10,10-20,20-30$ and $>30 \mathrm{ng} / \mathrm{mL}$. We evaluated the body weight prior to conception and during pregnancy. The peripheral levels of $25(\mathrm{OH}) \mathrm{D}$ were investigated using a standard assay in a central laboratory on the day of the sampling. RESULTS: We found significant correlation between vitamin D levels and age $(\mathrm{P}<0.0001)$, negative correlation with the BMI prior to conception $(\mathrm{P}<0.001)$ and at the time of the screening $(\mathrm{P}<0.0001)$, but no significant differences among the three trimesters concerning vitamin D levels. CONCLUSIONS: The levels of vitamin D among pregnant Bulgarian women are within the span of mild insufficiency, probably due to the normal BMI before and during the pregnancy. We noticed that with the increase of age, the more mature pregnant women have more responsible behavior and follow the advice of their obstetrician/gynecologist.
\end{abstract}

Keywords: Vitamin D, Pregnancy, Gestational Age, Body Mass Index, Age

\section{Introduction}

In the winter of 2012 Bulgarian Society of Endocrinology undertook a cross-sectional nested study on the levels of vitamin D and parathyroid hormone (PTH) among 2033 Bulgarians in 12 cities and the adjacent villages [1]. This study defined the threshold value of 25-hydroxyvitamin D [25 (OH) D] below which PTH levels increase $-50 \mathrm{nmol} / \mathrm{L}$ $(20 \mathrm{ng} / \mathrm{mL})$, i.e. this is the level of $25(\mathrm{OH}) \mathrm{D}$ needed to suppress PTH secretion. In this study $24.2 \%$ of the population had $25(\mathrm{OH})$ D levels above $50 \mathrm{nmol} / \mathrm{L}(20 \mathrm{ng} / \mathrm{mL})$ in the winter. In Bulgaria the food is not boosted with vitamin $\mathrm{D}$ and the majority of the adult population in this study have moderate to severe vitamin $\mathrm{D}$ deficiency. Moreover, this deficiency is more pronounced among females with no significant differences among different age groups. During the same year an additional seasonal follow-up of vitamin D levels was undertaken. This study encompassed part of the previously investigated individuals who had vitamin D deficiency or insufficiency. The investigation revealed that $8.5 \%$ of the studied population had vitamin D deficiency during the summer [2]. The levels of vitamin D were investigated in nursing homes for elderly and were compared to those of elderly individuals living in their own homes [3]. The comparative analysis showed significant differences between the two groups. Still, there is no data concerning the levels of vitamin D in pregnant women. These levels 
represent an important social issue.

According to the literature, the prevalence of vitamin D deficiency differs and depends on many factors, such as the season of the investigation, geographic characteristics, race, skin colour, food and living habits, etc. In a 2014 study of the Royal College of Obstetricians \& Gynaecologists, $47 \%$ of the Asian, $64 \%$ of the Middle East, 58\% of the black women and $13 \%$ of the Caucasian women living in London had vitamin D levels below $25 \mathrm{nmol} / \mathrm{L}$ [4]. Therefore, every screening program for vitamin $\mathrm{D}$ deficiency should be organized in accordance with the specific characteristics of the investigated population and the results retrieved are valid only for this particular population.

The aim of current study was to define the mean levels of $25(\mathrm{OH}) \mathrm{D}$ in pregnant Bulgarian women, to evaluate the prevalence of moderate to severe deficiency and the associations between these levels and the age, body weight before pregnancy and during the screening and with the term of pregnancy.

\section{Study Design}

We undertook a multicenter cross-sectional population-based study performed between September 25 and November 62019 in 10 Bulgarian cities $\left(41^{\circ}-44^{\circ} \mathrm{N}\right)$ with the adjacent villages (overall 84 settlements): Sofia, Samokov, Pirdop, Smolian, Gotze Delchev, Gabrovo, Troian, Burgas, Stara Zagora, Pleven. We established communication with 104 specialists in Endocrinology and Obstetrics and Gynecology, who invited more than 630 pregnant women to participate in the study. Overall 547 pregnant women consented $(86.83 \%)$.

\section{Materials and Methods}

We investigated 547 pregnant women, mean age $30 \pm 5$ years, median 30 years (18-47 years). The distribution of pregnant women according to their age is as follows: $18-22 \mathrm{y}$ - 33 (6\%), 23-27 y - 115 (21\%), 28-33 y - 219 (40\%), 34-37 $\mathrm{y}-128(23.4 \%), 38-42 \mathrm{y}-46(8 \%), 43-47 \mathrm{y}-6(1.1 \%)$. The allocation according to trimesters of pregnancy was: first trimester - 111 (20.3\%), second trimester - 275 (50.4\%), and third trimester - $161(29.3 \%)$. Prior to the study, all participants signed an informed consent approved by the local Ethics committee at the University Hospital Sofiamed (Protocol 14/16 Sept 2019), and the research was conducted in accordance with the Declaration of Helsinki. The investigated pregnant women were a random cohort, without pre-selection. All pregnant women filled in a questionnaire. Overall $457 / 547(83.55 \%)$ were taking medication (s) at the time of the investigation, mainly vitamin supplements $278 / 547(50.82 \%)$ as a monotherapy or in combination with other medications. All participants were Caucasians and none had liver or kidney diseases or malabsorption. The study did not require a sun exposure diary. During the previous months all pregnant women adhered to their usual daily routine.

In a previous population-based study [1], using adaptive regression analysis on the effect of $25(\mathrm{OH}) \mathrm{D}$ on PTH levels, we defined a cut-off value for hypovitaminosis D of $20 \mathrm{ng} / \mathrm{mL}$ $(50 \mathrm{nmol} / \mathrm{L})$. In this project was to determine both vitamin D deficiency in the Bulgarian population as a whole and its connection with gender and age. The levels below $10 \mathrm{ng} / \mathrm{mL}$ $(25 \mathrm{nmol} / \mathrm{L})$ were referred to as severe deficit, $10-20 \mathrm{ng} / \mathrm{mL}$ (25 - $50 \mathrm{nmol} / \mathrm{L})$ - a deficit similar to the criteria adopted at the Conference on this topic in Eibsee, Germany in 2012 [5]. In our current study we accepted sufficiency level above 30 $\mathrm{ng} / \mathrm{mL}(75 \mathrm{nmol} / \mathrm{L})$ and introduces additional degree of vitamin $\mathrm{D}$ insufficiency - between 20 and $30 \mathrm{ng} / \mathrm{mL}$ (50-75 $\mathrm{nmol} / \mathrm{L}$ ), based on the IOM recommendations [6] and Endocrine Society clinical practice guideline [7]. Whereas, the IOM recommendations define sufficiency as vitamin levels above $50 \mathrm{nmol} / \mathrm{L}(20 \mathrm{ng} / \mathrm{mL})$, the second guidelines suggest levels above $75 \mathrm{nmol} / \mathrm{L} \quad(30 \mathrm{ng} / \mathrm{mL})$, and both recommendations are in agreement with other expert opinions in the field $[8,9]$, that the optimum levels of vitamin D should be $75-125 \mathrm{nmol} / \mathrm{L}(\geq 30 \mathrm{ng} / \mathrm{mL})$ in order to preserve bone health. The latter is crucial during pregnancy for the formation of the fetal skeleton. Therefore, in pregnant women we suggest the following categories of $25(\mathrm{OH}) \mathrm{D}$ levels:

1. Severe deficiency (deficit): $<10 \mathrm{ng} / \mathrm{mL}$

2. Moderate deficiency (deficit): $10-20 \mathrm{ng} / \mathrm{mL}$

3. Insufficiency: $20-30 \mathrm{ng} / \mathrm{mL}$

4. Sufficiency: $>30 \mathrm{ng} / \mathrm{mL}$

All studied pregnant women filled in a specially designed questionnaire, concerning the course of the current pregnancy and pre-conception history (a structured questionnaire including demographic data, personal and family medical history, thyroid disorders, diabetes and chronic renal disease, past and current medication, vitamin $\mathrm{D}$ or other vitamin intake, etc.).

In every investigated pregnant woman we measured the body weight and height and the body weight before conception was documented in the Questionnaire. Based on the respective documented values, the body mass index (BMI) before conception and at the time of the investigation was calculated.

\subsection{Laboratory Test}

Morning blood sample was taken from the cubital vein and the total levels of $25(\mathrm{OH}) \mathrm{D}$ were determined using standard Electro Chemyluminescence Immuno Assay (Competition ECLIA method on Cobas 601 analyzer) in a central laboratory on the day of the sampling. Serum tubes containing separating gel were used. The samples were transported to the lab after centrifugation. The results are determined via a calibration curve in $\mathrm{ng} / \mathrm{mL}$. Two levels Intralaboratory quality control on a daily basis was performed. The Laboratory is participating in two EQA systems - Bulgarian EQAS and INSTAND and has certificates for this parameter.

\subsection{Statistical Processing}

The data were analyzed with SPSS for Windows v.13.0. descriptive statistics (mean, median values, standard 
deviation), correlation and dispersion analysis (using parametrical and non-parametrical methods, including Student's t-test, Kruskal-Wallis test and Mann-Whitney test.), ANOVA testing, post-hoc test - Bonferroni. All values were presented as mean values with standard deviations, median or percentage (unless specified otherwise), p values below 0.05 were accepted as statistically significant.

\section{Results}

Overall $84 \%$ of the investigated pregnant Bulgarian women were aged 23 - 37 years, half of them being $28-32$ years of age. A lower percentage of women were between 38 and 42 years $(8 \%)$ or $18-22$ years $(6 \%)$, and a very small percentage were in the age group $43-47$ years $(1.1 \%)$.

For the whole group (547 pregnant women), the mean 25 $(\mathrm{OH}) \mathrm{D}$ level was $25.86 \pm 9.46 \mathrm{ng} / \mathrm{mL}$; median 24.51 (7.96 70.00), corresponding to mild insufficiency during the autumn. Table 1 presents the four groups according to vitamin D levels - severe deficiency, deficiency, insufficiency and sufficiency.

Table 1. The prevalence of different four level vitamin D-severe deficiency, deficiency, insufficiency, sufficiency in cohort of pregnant women.

\begin{tabular}{lllll}
\hline & Category (group) & $\begin{array}{l}\mathbf{2 5}(\mathbf{O H}) \mathbf{D} \text { level } \\
(\mathbf{n g} / \mathbf{m l})\end{array}$ & Number & $\mathbf{\%}$ \\
\hline 1 & Severe deficiency & $<10$ & 7 & 1.28 \\
2 & Deficiency & $10-20$ & 141 & 25.78 \\
3 & Insufficiency & $20-30$ & 251 & 45.88 \\
4 & Sufficiency & $\geq 30$ & 148 & 27.06 \\
\hline
\end{tabular}

Only $27.06 \%$ of the investigated pregnant women had sufficient levels of $25(\mathrm{OH}) \mathrm{D}$ above $30 \mathrm{ng} / \mathrm{L}$ (group 4) and the other three groups (1,2 and 3) had deficiency or insufficiency-72.94\%. The mean age of the investigated cohort was $30.49 \pm 5.12$ years. The group $4(\mathrm{n}=148)$ with 25 $(\mathrm{OH}) \mathrm{D} \geq 30 \mathrm{ng} / \mathrm{mL}$ was aged $31.39 \pm 5.02$ years, compared to $30.16 \pm 5.13$ years for groups 1 plus 2 plus $3(\mathrm{n}=399)$, where $25(\mathrm{OH})$ D levels were below $30 \mathrm{ng} / \mathrm{mL}(\mathrm{P}<0.02)$.

The mean BMI before pregnancy for the whole cohort was $23.57 \pm 6.9 \mathrm{~kg} / \mathrm{m}^{2}$; median $22.15(15.24-133.33)$, at the screening (i.e. during pregnancy) - $26.15 \pm 7.28 \mathrm{~kg} / \mathrm{m}^{2}$; median 25.30 (16.51-147.22).

The mean body weight before pregnancy for the whole cohort was $63.68 \pm 14.36 \mathrm{~kg}$, at the screening (during pregnancy) $-70.60 \pm 14.50 \mathrm{~kg}$. Before the pregnancy the mean weight of group 4 was $61.27 \pm 11.89 \mathrm{~kg}$, and for the other three groups $-64.57 \pm 15.09 \mathrm{~kg}(\mathrm{P}<0.034)$. The respective body weight at the screening was $67.45 \pm 12.79 \mathrm{~kg}$ in group 4 compared with $71.76 \pm 14.94 \mathrm{~kg}$ for groups 1 plus 2 plus $3(\mathrm{P}<0.002)$.

The average levels of vitamin $\mathrm{D}$ in the first, second and third trimesters were $25.97 \pm 10.28,25.34 \pm 8.89$ and $26.70 \pm$ $9.84 \mathrm{ng} / \mathrm{mL}$, respectively, with no significant differences between the subgroups (NS).

We found significant correlation of vitamin D levels and: age [Spearman's rho $=0.151, \mathrm{P}<0.0001$ ], negative correlation with BMI before pregnancy [Spearman's rho = -
0.142, $\mathrm{P}<0.001$ ] and BMI at the screening [Spearman's rho $=-0.171, \mathrm{P}<0.0001]$; and no correlation between vitamin $\mathrm{D}$ levels and the gestational age $(\mathrm{P}=\mathrm{NS})$.

\section{Discussion}

In their study on the role of vitamin D supplementation during pregnancy, Luz Maria De-Regil et al. (2019) suggest that during pregnancy decreases the risk of preeclampsia, gestational diabetes and low fetal birth weight [10]. This is in harmony with the findings of other studies on vitamin $\mathrm{D}$ in pregnancy $[11,12]$. Despite the unclear role of vitamin D supplementation, all authors are in accordance that such prevention should be administered [4].

In our pregnant cohort, the first thing that could be noted is the change in the age profile of the Bulgarian pregnant women in the past few years. Compared to the 2015 Euro-Peristat Project population [13], five years later, in 2019, the percentage of pregnancies below the age of 20 has decreased in Bulgaria (from $10.2 \%$ to $2.74 \%$, respectively), as well as in the range between 20 and 24 years (from $21.7 \%$ to $7.9 \%$, respectively). At the same time there is an increase in the percentage of pregnant women between 25 and 34 years (from $54.5 \%$ to $68.52 \%$ ) and $35+$ years (from $13.6 \%$ to $20.84 \%$, respectively), figure 1 .

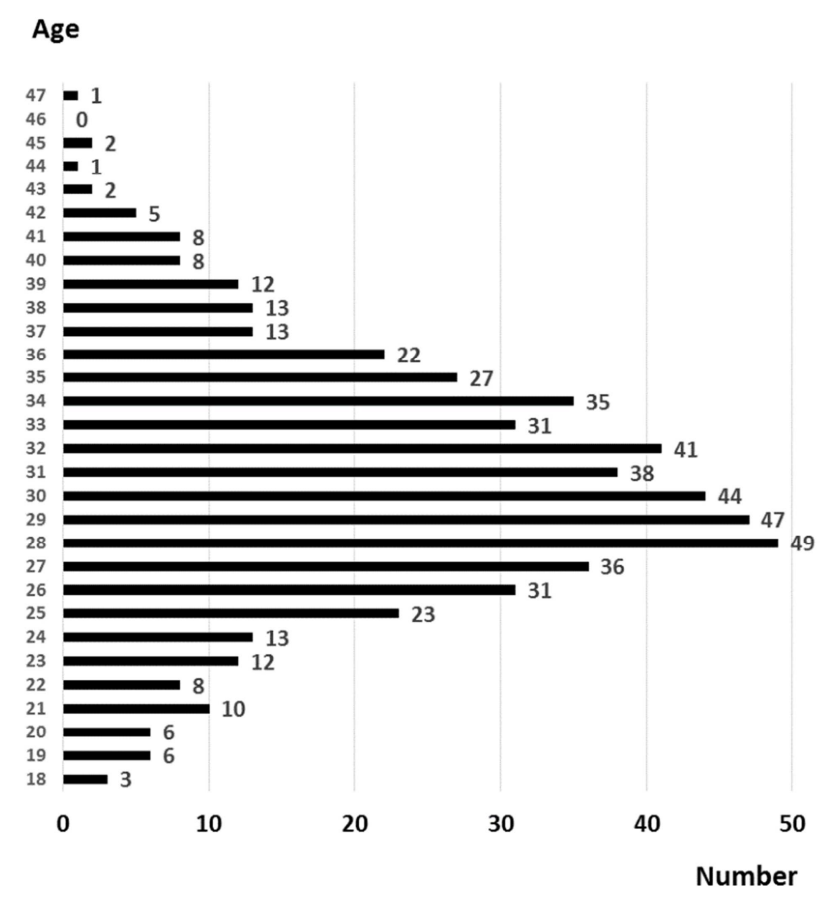

Figure 1. Age distribution of 547 pregnant Bulgarian women - 2019.

What is the importance of this phenomenon? The described shift in the age distribution is a good sign for maturation of the society as a whole. The well informed and educated adult female individual with experience could take better care for the desired pregnancy. A confirmation of this hypothesis is the fact that in group 4 (with the highest levels of $25(\mathrm{OH}) \mathrm{D} \geq 30 \mathrm{ng} / \mathrm{mL})$ the mean age is significantly 
higher than in groups 1,2 and 3 (who have vitamin D insufficiency): $31.39 \pm 5.02$ years vs $30.16 \pm 5.13$ years, respectively, $\mathrm{P}<0.02$. Moreover, the "older" young women desire pregnancy more and have more interest in taking adequate pregnancy care. These more mature women better understand their higher responsibility towards the unborn baby and change their lifestyle and habits, undertake investigations, consultations and take medications and supplements if needed. These women have better values of two other indicators in the pregnancy questionnaire smoking during the current pregnancy and normal BMI pre-conception, both included in the Euro-Peristat Project, 2015 [13]. Both indicators have been thoroughly discussed by J. Zeitlin et al [14].

Concerning the mean $25(\mathrm{OH})$ D levels of $25.86 \pm 9.46$ $\mathrm{ng} / \mathrm{mL}$ (median 24.51, 7.96 - 70.00), we could conclude that there is a mild insufficiency within the whole group of 547 pregnant women. We cannot compare the population results from September-October $2012(52.75 \mathrm{nmol} / \mathrm{L}=21.18 \mathrm{ng} / \mathrm{mL})$ with the results of our present study, because of the different demographics in both investigations: the 2012 study included men and women aged 20-80 years, the selection of the participants was different (individuals with pre-diagnosed deficiency / insufficiency in winter, who were instructed not to take vitamin D supplements). In general, the levels of 25 $(\mathrm{OH}) \mathrm{D}$ are lower in women, but higher in younger age. Moreover, $30 \%$ of the studied pregnant women are from small towns and villages where the mean levels of vitamin D are higher [15].

Another study of pregnant women in Belgium $\left(46^{\circ} \mathrm{N}\right)$ was performed between September and June and vitamin D levels were followed up during different trimesters, but some of the pregnant women were of North-African descend. Again, because of the different design and the presence of two races, different lifestyles, food habits and body coverage of the investigated women the results are not comparable with our study. Moreover, Belgium is located more to the North, and $74 \%$ of the women have vitamin D insufficiency [25 (OH) D $<30 \mathrm{ng} / \mathrm{mL}$ ], 44\% have deficiency [25 $(\mathrm{OH}) \mathrm{D}<20 \mathrm{ng} / \mathrm{mL}$, and $12 \%$ have severe deficiency [25 $(\mathrm{OH}) \mathrm{D}<10 \mathrm{ng} / \mathrm{mL}$ ] [16]. These examples only illustrate the two phenomena, observed in our study: 1) Severe deficiency is observed in a different percentage of the pregnant women ( $12 \%$ in Belgium versus $1.28 \%$ in our study); 2) All studies (including our investigation) have used the same criteria for the evaluation of vitamin D status with the universal cut-off points recommended by the relevant international authorities.

The negative correlation between the body weight and the levels of vitamin D is a well-known fact. Probably this is one of the factors determining the higher $25(\mathrm{OH})$ D levels in group 4 where the body weight was lower both before and during pregnancy compared to that in groups 1,2 and 3 (before pregnancy $-61.27 \pm 11.89 \mathrm{~kg}$ vs $64.57 \pm 15.09 \mathrm{~kg}, \mathrm{P}$ $<0,034$; during pregnancy $-67.45 \pm 12.79 \mathrm{~kg}$ vs. $71.76 \pm$ $14.94 \mathrm{~kg}, \mathrm{P}<0,002)$. An additional factor is the weight gain during pregnancy $-6 \mathrm{~kg}$ in group 4 and $7 \mathrm{~kg}$ in groups 1,2 and 3 , respectively. We should underline that both before and during pregnancy the investigated women had normal mean BMI $\left(23.57 \pm 6.9\right.$ and $26.15 \pm 7.28 \mathrm{~kg} / \mathrm{m}^{2}$, respectively).

In our study, the role of age, body weight and the intake of vitamin supplements on vitamin D levels during pregnancy is clear, and the term of pregnancy does not affect vitamin D status.

\section{Conclusion}

The levels of vitamin D among pregnant Bulgarian women are within the span of mild insufficiency, probably due to the intake of combined vitamin supplements by approximately half of the studied women, and the normal BMI before and during the pregnancy. The more mature age at the time of pregnancy and the more responsible behavior and care aid the adherence to the advice given by their obstetrician/gynecologist.

\section{Acknowledgements}

The authors thank the endocrinologists and obstetrician/gynecologists who provided local support: V. Jotova (Troyan), S. Dimitrova (Gabrovo), Anchev (Gabrovo), Mitev (Gabrovo), A. Popov (Goce Delchev), A. Andreev (Samokov), E. Apostolova (Smolyan), M. Hubshev (Smolyan), S. Dimitrov (Pirdop), R. Naumovska (Pleven), M. Manuelyan (Burgas), K. Kirovakov (Burgas), K. Venkova (Sofia), M. Angelova (Stara Zagora), R. Velev (Sofia), I. Sigridov (Sofia), B. Bogoslovova (Sofia) ... total 104 specialists in the country. Technical support: T. Kornilova (Sofia), Z. Metodieva (Sofia), J. Georgieva (Sofia), H. Atanasova (Burgas), I. Ilieva (Stara Zagora).

This work was supported by grants from the Bulgarian Society of Endocrinology as part of the National Epidemiological Program for Pregnant Women in Bulgaria 2019.

\section{Conflicts of Interests}

All the authors do not have any possible conflicts of interest.

\section{References}

[1] Borissova A-M, Shinkov A, Vlahov J, Dakovska L, Todorov T, Svinarov D, Kassabova L. (2013). Vitamin D status in Bulgaria winter data. Arch. Osteoporosis 8: 133-137.

[2] Borissova A-M, Shinkov A, Vlahov J, Dakovska L, Todorov T, Kassabova L. and Svinarov D. (2015). Dynamic of the seasonal levels of $25(\mathrm{OH}) \mathrm{D}$ in Bulgaria according to sex, age and winter status of vitamin D. Nutrition and Aging 3, 2-4: 107-113.

[3] Shinkov A, Borissova A-M, Dakovska L, Vlahov J, Kassabova L, Svinarov D, Krivoshiev S. High prevalence of vitamin $\mathrm{D}$ deficiency and secondary hyperparathyroidism in nursing home residents. (2016). Archives of Endocrinology and Metabolism 23; 60 (3): 217-222.

[4] College of Obstetricians\&Gynaecologists, Vitamin D in pregnancy, Scientific Impact Paper N43, June 2014. 
[5] Bischoff-Ferrari HA. (2012). Vitamin D-why does it matter? defining vitamin D deficiency and its prevalence. Scand J Clin Lab Investig 72 (Suppl 243): 3-6.

[6] Rosen CJ, Abrams SA, Aloia JF, Brannon PM, Clinton SK, Durazo-Arvizu RA, Gallagher JC, Gallo RL, Jones G, Kovacs CS, Manson JE, Mayne ST, Ross AC, Shapses SA, Taylor CL. (2012). IOM committee members respond to Endocrine Society vitamin D guideline. J Clin Endocrinol Metab 97 (4): 1146-1152.

[7] Holick MF, Binkley NC, Bischoff-Ferrari HA, Gordon CM, Hanley DA, Heaney RP, Murad MH, Weaver CM. (2011). Evaluation, treatment, and prevention of vitamin D deficiency: an Endocrine Society clinical practice guideline. J Clin Endocrinol Metab 96 (7): 1911-1930.

[8] Dawson-Hughes B, Heaney RP, Holick MF, Lips P, Meunier PJ, Vieth R. (2005). Estimates of optimal vitamin D status. Osteoporos Int 16: 713-716.

[9] Dawson-Hughes B. Vitamin D deficiency in adults: Definition, clinical manifestations and treatment. Up To Date Review. 6 January 2017. Sector Editors: Marc K. Drezner, Clifford J Rosen. Deputi Editor: Jean E Mulder. Access date 19 January 2019. Available from: https://www.uptodate.com/contents/vitamin-ddeficiency-in-ad ults-definition-clinical-manifestations-and-treatment.

[10] De-Regil LM, Palacios C, Ansary A, Kulier R, Pena-Rosas JP. Vitamin D supplementation for women during pregnancy. Cochrane Systematic Review - Intervention Version published: 26 July 2019.
[11] Zhang M-Xi, Guo-Tao Pan, Jian-Fen Guo, Bing-Yan Li, Li-Quang Qin, Zeng-Li Zhang. (2008). Maternal plasma 25-hydroxyvitamin D concentrations and the risk for gestational diabetes mellitus. Public Library of Science One 3: e3753.

[12] Lefelaar ER, Vrijkotte TG, van Eijsden M. (2010). Maternal early pregnancy. Children and their Development cohort. British Journal of Nutrition 104: 108-117.

[13] Euro-Peristat Project. European Perinatal Health Report. Core indicators of the health and care of pregnant women and babies in Europe in 2015. November 2018. www.europeristat.com.

[14] Zeitlin J, Wildman K, Breart G, Alexander S. Barros H, Blondel B, Buitendijk S, Gissler M, Macfarlane A. (2003). Selecting an indicator set for monitoring and evaluating perinatal health in Europe: criteria, methods and results from the PERISTAT project. Eur J Obstet Gynecol Reprod Biol 111 Suppl 1: S5-S14.

[15] Borissova A-M, Shinkov A, Vlahov J, Dakovska L, Todorov T, Svinarov D, Kassabova L. (2012). Comparative analysis on distribution of deficiency and insufficiency of vitamin D in different types living places in Bulgaria. Endocrinologia 3, 3, 143-157.

[16] Vandevijvere S, Amsalkhir S, Van Oyen H, Moreno-Reyes R. (2012). High Prevalence of Vitamin D Deficiency in Pregnant Women: A National cross-sectional survey. PLoS ONE 7 (8): e43868. doi: 10.1371/journal.pone.0043868. 